\title{
THE EFFECTS OF CHLORMADINONE ACETATE (CMA), ANTIANDROGEN, ON THE PITUITARY, TESTIS, PROSTATE AND ADRENAL GLAND OF THE DOG WITH SPONTANEOUS BENIGN PROSTATIC HYPERPLASIA
}

\author{
Masanori MURAKOSHI, Rie IKEDA and Norio FUKUI \\ Safety Research Department, Teikoku Hormone Mfg. Co., Ltd., \\ 1604 Shimosakunobe, Takatsu-ku, Kawasaki-city, Kanagawa 213-8522, Japan
}

(Received October 30, 2000; Accepted April 10, 2001)

\begin{abstract}
The effect of chlormadinone acetate (CMA), a synthetic steroidal antiandrogen, on spontaneous benign prostatic hyperplasia (BPH) in dogs was investigated. Male beagle dogs (5-8 years old) were divided into four experimental groups. Group 1 consisted of untreated controls. Groups 2 and 3 received CMA 0.03 and $0.1 \mathrm{mg} / \mathrm{kg} /$ day, p.o., respectively, for 6 months. In group 1, glandular hyperplasia of the prostate was clearly detected. The glandular epithelial cells showed uniformly intense nuclear staining for androgen receptor (AR). AR was also localized in the nuclei of the fibro-muscular stromal cells. In groups 2 and 3, CMA produced marked atrophy of the glandular epithelium. The interacinar fibro-muscular stroma was prominent. The nuclear staining for AR in both epithelial and stromal cells was remarkably decreased. In addition, a histopathological study showed that CMA medication for 6 months exerted no effect on the testes and adrenal glands or on immunoreactive positive cells to LH- and ACTH-antibody (pituitary LH- and ACTH-cells). Therefore, it is concluded that CMA $(0.03$ and $0.1 \mathrm{mg} / \mathrm{kg})$ causes regression of spontaneous canine BPH without any histopathological effects on the testes, adrenal glands or pituitary LH- and ACTH-cells.
\end{abstract}

KEY WORDS: Benign prostatic hyperplasia (BPH), Beagle dog, Androgen receptor (AR), Chlormadinone acetate (CMA), LH cells, ACTH cells

\section{INTRODUCTION}

Among laboratory animals, the dog is the only species that spontaneously develops benign prostatic hyperplasia (BPH) with a high frequency (Walsh and Wilson, 1976; DeKlerk et al., 1979). Canine BPH is believed by many investigators to be an appropriate model for the study of human BPH, although there are important differences between the conditions in the two species (Geller et al., 1975; Okada et al., 1988; Tunn et al., 1988; Forti et al., 1989). The human disease is often a multinodular process thought to arise in a periurethral stromal nodule, which is then secondarily invaded by glandular elements (Harada et al., 1994). In contrast, canine BPH is a diffuse epithelial or glandular process with less stromal involvement (DeKlerk et al.,
1979). Although some differences exist between human and canine BPH, the dog is considered to be a good animal model of BPH to test the efficacy of drugs that cause shrinkage of the hyperplastic gland (Geller $e t$ al., 1975; Okada et al., 1988; Tunn et al., 1988; Forti et al., 1989).

Chlormadinone acetate (CMA)(Fig. 1) is a steroidal antiandrogen that is widely used in the medical management of BPH in Japan (Ito et al., 1977; Harada et al., 1994). It is a well-documented fact that CMA inhibits the uptake of testosterone in the prostate and is selectively incorporated into prostate cells, resulting in inhibiting testosterone binding to the cytosol 5 alpha-dihydrotestosterone (DHT)-receptor (Ito et al., 1977; Takezawa et al., 1992,1995).

Previously, the atrophic effect of a synthetic 
steroidal antiandrogen, CMA, on spontaneous BPH in dogs was investigated (Murakoshi et al., 2000). As a results, CMA produced marked atrophy of the glandular epithelium and the interacinar fibro-muscular stroma was prominent. Furthermore, the intensity of the immunostaining for androgen receptor (AR), 5 alphareductase type I and type II was negative or very weak under CMA treatment. Therefore, it is concluded that atrophy after treatment with CMA may be due to shrinkage of both glandular and stromal compartments in the prostate tissue (Murakoshi et al., 2000).

In humans, BPH is the result of an increase in both glandular and stromal compartments (Wilson, 1980). Therefore, it is suggested that effects on both compartments are required to achieve the intended clinical benefits in patients treated with CMA.

On the other hand, the atrophic effects (glucocorticoid-like activity) of cyproterone acetate (CPA) and CMA on the adrenal glands of rats have been reported by several authors (Brennan and Kraay, 1963; Starka et al., 1972). Furthermore, it is well known that the above steroidal antiandrogens inhibit gonadotropin (LH) secretion and testosterone biosynthesis, unlike nonsteroidal antiandrogens, which produce increases in LH and testosterone when given alone (Namer, 1988).

The purpose of the present study was to further examine the effect of CMA on canine spontaneous $\mathrm{BPH}$. The effects of CMA on testicular, adrenal morphology, pituitary LH- and ACTH-cells were also investigated.

\section{MATERIALS AND METHODS}

\section{Animals}

Thirty male beagle dogs were purchased from

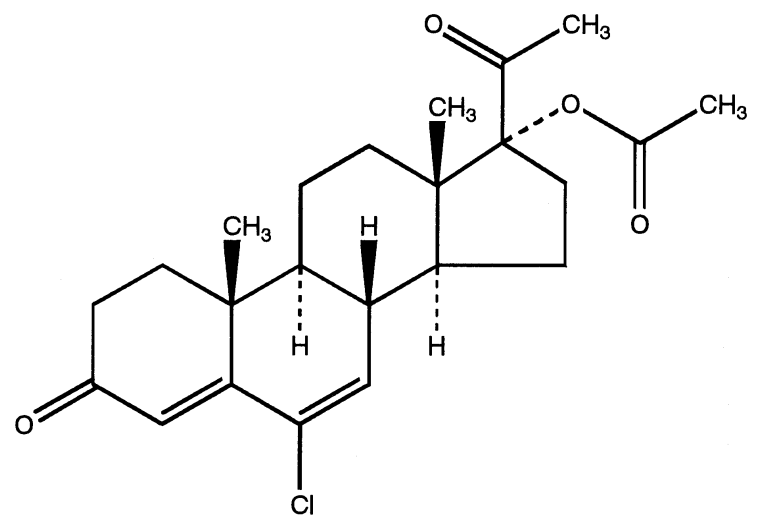

Fig. 1. Chemical structure of chlormadinone acetate (CMA).
Hazelton Research Product, Inc. (Denver, PA). The animals were housed individually in stainless steel cages at a room temperature of $22 \pm 3^{\circ} \mathrm{C}$, and relative humidity of $60 \pm 20 \%$, with $12 \mathrm{hr}$ of light (7:00-19:00). The animals were given $300 \mathrm{~g}$ of a standard diet (CD-1, CLEA Japan, Inc.) daily and tap water ad libitum. They were 5-8 years old and contained BPH on the basis of biopsy (data not shown).

\section{Experiments}

Four animals served as BPH untreated controls (group 1). Groups 2 and 3 were administered orally 0.03 (group 2, n=4) and 0.1 (group 3, n=4) $\mathrm{mg} / \mathrm{kg} /$ day of CMA as a crystalline powder in gelatin capsules for 6 months. All animals were sacrificed by exsanguination under pentobarbital anesthesia at the end of the experimental period.

\section{Organ weight}

The weights of the prostates, pituitary glands, testes and adrenal glands were recorded (absolute weight). Weights relative to body weight (relative weight) were calculated.

\section{Histopathological examination}

The prostates, pituitary glands, testes and adrenal glands were removed immediately, fixed in $0.1 \mathrm{M}$ phosphate-buffered $10 \%$ formalin and embedded in paraffin. Cut sections were mounted and stained with hematoxylin and eosin (HE).

\section{Immunohistochemical staining 1. Androgen receptor (AR)}

The prostates were frozen in dry-ice-cooled ethanol. Frozen sections ( $6 \mu \mathrm{m}$ in thickness) were prepared in a cryostat and mounted on glass slides. The sections were fixed for $10 \mathrm{~min}$ at $4^{\circ} \mathrm{C}$ in Zamboni's fixative (Zamboni and McMartino, 1967). After washing in $0.01 \mathrm{M}$ phosphate-buffered saline (PBS) containing $20 \%$ sucrose, the sections were soaked in absolute methanol containing $0.3 \%$ hydrogen peroxide for 30 $\mathrm{min}$ at room temperature to inactivate endogenous peroxidase. After washing in $0.01 \mathrm{M}$ PBS, the sections were incubated overnight at $4^{\circ} \mathrm{C}$ with $\mathrm{NH} 27$, a rabbit polyclonal antiandrogen receptor antibody (1:1000). After washing in $0.01 \mathrm{M}$ PBS, the sections were covered with biotin-conjugated goat anti-rabbit IgG for 1 $\mathrm{hr}$, washed in $0.01 \mathrm{M}$ PBS and then treated with streptavidin-biotin-peroxidase complex (Histofine, SAB-PO (R) Kit, Nichirei, Tokyo) for $1 \mathrm{hr}$. After incubation was completed, the sections were treated for 5 to $10 \mathrm{~min}$ at 
room temperature with Graham-Karnovsky's reaction medium (Graham and Karnovsky, 1966), which contained $20 \mathrm{mg}$ of 3,3'-diaminobenzidine (DAB, Wako Pure Chemical Industries, Osaka) and $0.05 \%$ hydrogen peroxide in $0.05 \mathrm{M}$ Tris- $\mathrm{HCl}$ buffer, $\mathrm{pH}$ 7.6. The sections were finally counterstained for nuclei with $1 \%$ methyl green dissolved in veronal acetate buffer, $\mathrm{pH}$ 4.2.

\section{LH- and ACTH-cells}

Formalin fixed and paraffin sections were used. Rabbit antisera against bovine LH (UCB-Bioproducts, Belgium) and porcine ACTH (Advance, Tokyo) were used. The specificity of these antisera for staining LHand ACTH-cells have been evaluated previously (El Etreby and Fath El, 1977). The antisera at 1:1000 dilution were incubated with the sections at room temperature for $30 \mathrm{~min}$. Then, the sections were covered with biotin-conjugated goat anti-rabbit IgG for $1 \mathrm{hr}$, washed in $0.01 \mathrm{M}$ PBS and then treated with streptavidinbiotin-peroxidase complex (Histofine, SAB-PO (R) Kit, Nichirei, Tokyo) for $1 \mathrm{hr}$. After incubation was completed, the immunoperoxidase staining was performed as described above. The number of cells per visual field of light microscope was counted at $\times 400$. Ten fields were examined and averaged for each group.

\section{Statistical analysis}

The data were expressed as mean \pm SD. Homogeneity of variance was tested by Bartlett's method (Yoshimura, 1997), and when the assumption of homogeneity of variance was met, one-way layout analysis of variance was performed. When a significant difference was observed, Scheff's or Dunnett's multiple comparative test (Yoshimura, 1997) was performed between the control group and the other experimental groups.

\section{RESULTS}

\section{Organ weight}

As shown in Table 1, absolute and relative weights of the prostates in group 3, and absolute weights of the prostates in group 2 were statistically significantly $(\mathrm{p}<0.05)$ reduced, compared to the control values. In contrast, pituitary, testicular and adrenal weights showed no significant differences among the groups (Table 1).

\section{Light microscopic findings \\ 1. Prostates}

In group 1, glandular epithelial cells were markedly hypertrophic and showed an increased number of papillary projections extending into the acini (Photo 1A). Thus, histological features of glandular hypertrophy and/or hyperplasia were evident (Table 2). The amount of interacinar stroma was variable but not extensive. The glandular epithelial cells showed uniformly intense nuclear immunostaining for AR (Photo 2A). AR was also localized in the nuclei of the fibromuscular stromal cells.

In CMA-treated animals (groups 2 and 3), the glandular epithelial cells were markedly atrophic and the acini completely atrophic (Photo 1B). Thus, histological features of glandular atrophy were evident. In contrast, the interacinar fibro-muscular stroma was prominent (Table 2). By CMA-administration, intensity of the immunoreaction for AR was dose-dependently decreased in both glandular epithelial cells and fibromuscular stromal cells (Photo 2B).

\section{Testes}

No evidence of abnormal spermatogenesis was seen in the seminiferous tubules. No changes in the Leydig cell population were found. No evidence of Leydig cell hyperplasia or atrophy was observed in any of the experimental groups.

\section{Adrenal glands}

No conspicuous changes were noted in any of the experimental groups.

\section{Pituitary LH- and ACTH-cells}

LH cells were located mainly in the dorsal region of the pars distalis. Administration of CMA produced no significant treatment-related changes in the number of immunoreactive cells (Table 1). ACTH cells were located in both pars distalis and pars intermedia. Administration of CMA produced no significant treatment-related changes in the number of immunoreactive cells (Table 1).

\section{DISCUSSION}

In the present study, CMA produced marked atrophy of the glandular epithelium. In addition, loss of secretory and metabolic activities was evident. These findings were in good agreement with previous findings (Murakoshi et al., 2000). It is a well-documented fact that CMA inhibits the uptake of testosterone in the 
M. MURAKOSHI et al.

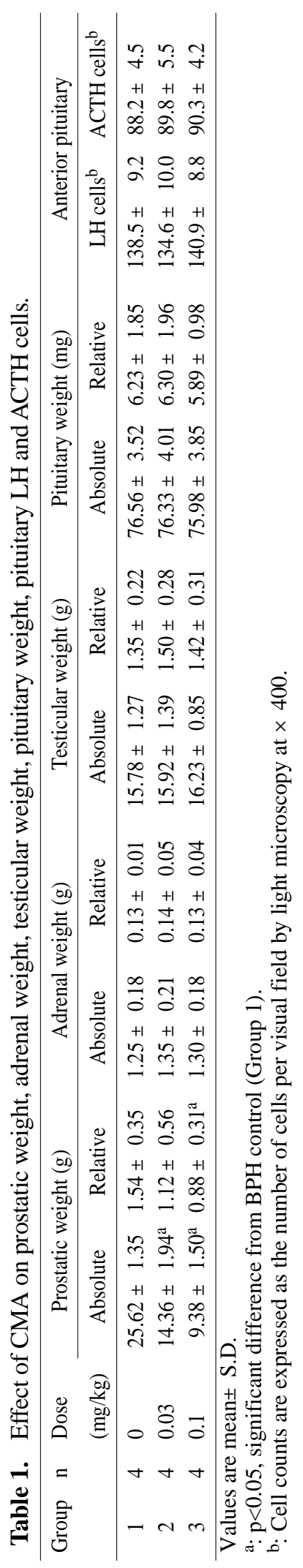

Vol. 26 No. 3 
Effect of CMA on canine spontaneous BPH.

prostate and is selectively incorporated into prostate cells, resulting in inhibiting testosterone binding to the cytosol 5 alpha-DHT-receptor (Ito et al., 1977; Takezawa et al., 1992, 1995). Thus, the uptake of testosterone and/or its androgenic effect on the prostate may be suppressed by CMA. In fact, immunostaining of nuclear AR in both epithelial and fibro-muscular stromal cells was markedly decreased after treatment with CMA. It is further well-documented that prostatic nuclear AR contents were decreased after treatment with gonadotropin-releasing hormone $(\mathrm{GnRH})$ agonist (Forti et al., 1989) as well as CPA (Huang et al., 1985), an antiandrogenic agent. Based on our present data and these facts, decreased immunostaining of AR after treatment with CMA may be explained by a decrease in the number of AR. In fact, CMA inhibits the binding to androgen and AR competitively (data not shown). Therefore, CMA binds competitively to the AR from the prostate, and dose-dependent oral administration causes regression of the hyperplastic prostatic weight.

Table 2. Histopathological findings.

\begin{tabular}{|c|c|c|c|c|}
\hline \multirow{2}{*}{ Organ } & \multirow{2}{*}{ Findings } & \multicolumn{3}{|c|}{ CMA (mg/kg) } \\
\hline & & $\begin{array}{c}0 \\
(\mathrm{n}=4)\end{array}$ & $\begin{array}{c}0.03 \\
(\mathrm{n}=4)\end{array}$ & $\begin{array}{c}0.1 \\
(\mathrm{n}=4)\end{array}$ \\
\hline \multirow[t]{13}{*}{ Prostate } & Glandular hypertrophy/hyperplasia & 4 & 0 & 0 \\
\hline & Glandular atrophy & & & \\
\hline & Mild & 0 & 3 & 2 \\
\hline & Moderate & 0 & 1 & 1 \\
\hline & Severe & 0 & 0 & 1 \\
\hline & Prominence of fibro-muscular stron & & & \\
\hline & Mild & 0 & 3 & 2 \\
\hline & Moderate & 0 & 1 & 1 \\
\hline & Severe & 0 & 0 & 1 \\
\hline & Decreased number of AR-positive & cells & & \\
\hline & Mild & 0 & 3 & 2 \\
\hline & Moderate & 0 & 1 & 1 \\
\hline & Severe & 0 & 0 & 1 \\
\hline \multirow[t]{4}{*}{ Testis } & Atrophy of seminiferous tubules & & & \\
\hline & Mild & 0 & 0 & 0 \\
\hline & Moderate & 0 & 0 & 0 \\
\hline & Severe & 0 & 0 & 0 \\
\hline \multirow[t]{4}{*}{ Adrenal } & Atrophy of cortex & & & \\
\hline & Mild & 0 & 0 & 0 \\
\hline & Moderate & 0 & 0 & 0 \\
\hline & Severe & 0 & 0 & 0 \\
\hline \multirow[t]{2}{*}{ Pituitary } & Decreased number of LH cells & 0 & 0 & 0 \\
\hline & Decreased number of ACTH cells & 0 & 0 & 0 \\
\hline
\end{tabular}

The AR is a member of a steroid superfamily of ligand-inducible intracellular regulators that activate or repress transcription of target genes (Chang and Kokonitis, 1988). ARs are structurally and functionally organized into domains that mediate hormone binding, nuclear translocation, dimerization, DNA binding, and transcriptional activation (Beato, 1989; Carson-Jurica et al., 1990). It is, therefore, conceivable the CMA might present receptor dimerization, might increase AR turnover, and thus reduce AR content. Further studies are needed to clarify the way in which CMA reduces AR.

It is well known that steroidal antiandrogens such as CPA inhibit gonadotropin (LH) secretion and testosterone biosynthesis (Namer, 1988). The present histopathological study showed that CMA (0.03 and $0.1 \mathrm{mg} / \mathrm{kg}$ ) medication for 6 months exerted no effect on the testes or pituitary LH cells. Therefore, it is suggested that CMA in smaller doses $(0.1 \mathrm{mg} / \mathrm{kg}$ or less $)$ causes regression of spontaneous canine BPH without any significant histopathological changes in the testes or pituitary LH cells.

It is generally accepted that CMA has some glucocorticoid-like activities in rodents, and suppression of adrenal function is evident in rodents (Brennan and Kraay, 1963; Givner and Rochefort, 1972). The present study showed that CMA $(0.03$ and $0.1 \mathrm{mg} / \mathrm{kg})$ medication for 6 months exerted no effect on the adrenal glands or pituitary ACTH cells. Therefore, it is suggested that CMA in smaller doses $(0.1 \mathrm{mg} / \mathrm{kg}$ or less) causes regression of spontaneous BPH without any significant histopathological changes in the adrenal glands or pituitary ACTH cells.

AR has been observed exclusively in the nuclei of the adrenal cortical cells (Murakoshi et al., 1994). The male and female adrenal showed the same pattern of AR staining. It is believed that adrenal androgens are secreted by zona reticularis. Thus, AR in the adrenal cortical cells may be involved in an autocrine function. Previously we found that AR was also localized in the nuclei of the rat adrenal cortical cells of the atrophic cortical zones induced by CMA treatment (Murakoshi et al., 1994). Pham-Huu-Tung et al. (1984) reported that CPA, an antiandrogen, decreased cortisol production and increased adrenal androgen levels. Androgens have been shown to increase both synthesis (Blondeau et al., 1982; Syms et al., 1985) and half-life of AR (Syms et al., 1985), which result in elevated receptor protein levels within the tissues. Therefore, it is suggested that rat adrenal cortical cells of the atrophic cortical zones induced by CMA treatment were decreased 

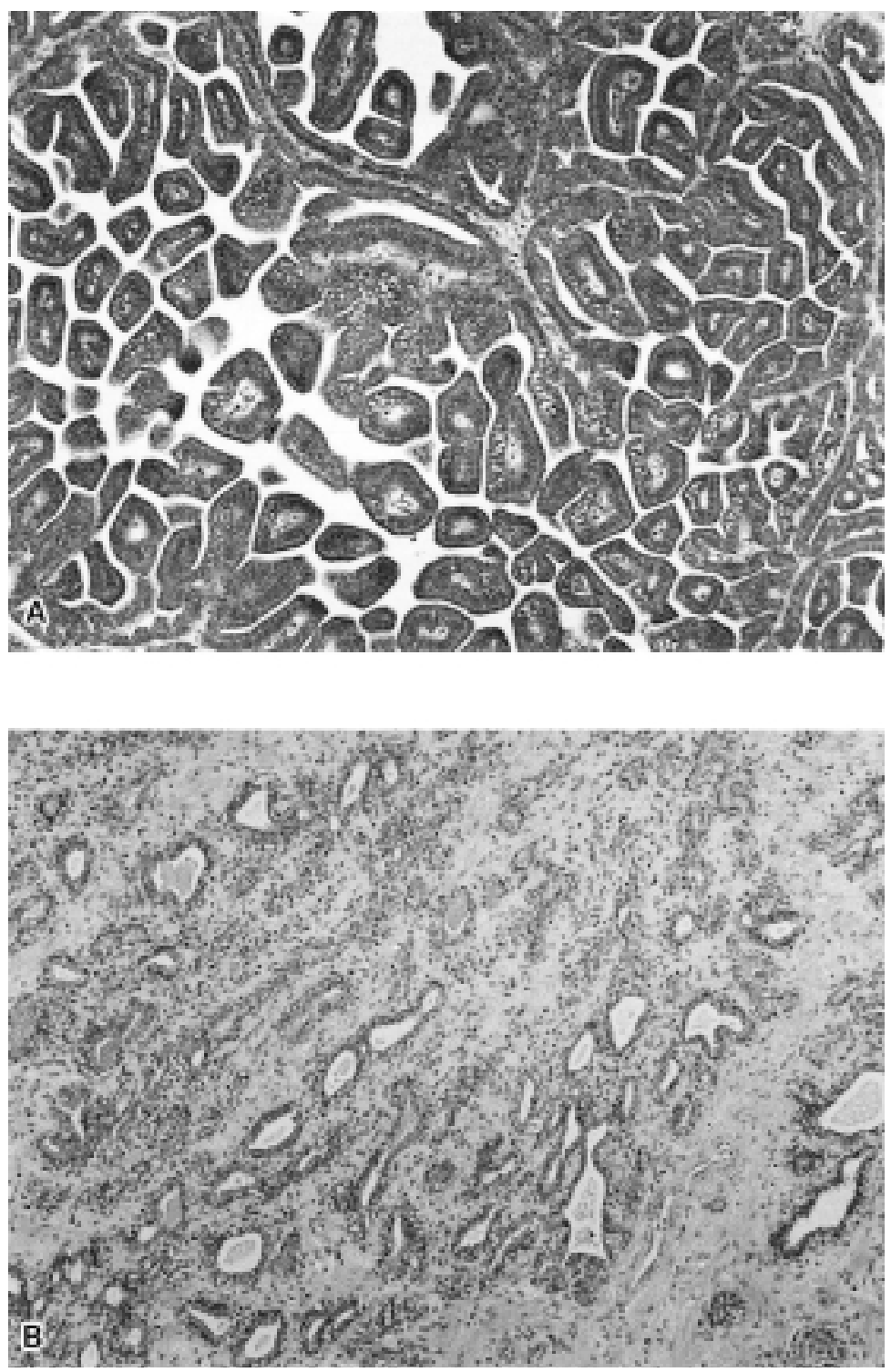

Photo 1. A: Prostate of a dog with spontaneous BPH. Glandular hyperplasia is dominant. $\mathrm{HE}, \times 150$.

$\mathrm{B}$ : Prostate of a dog with spontaneous BPH after treatment with CMA $0.1 \mathrm{mg} / \mathrm{kg} /$ day. The glandular epitheli$\mathrm{um}$ is atrophic, and interacinar stroma is prominent. HE, $\times 250$. 

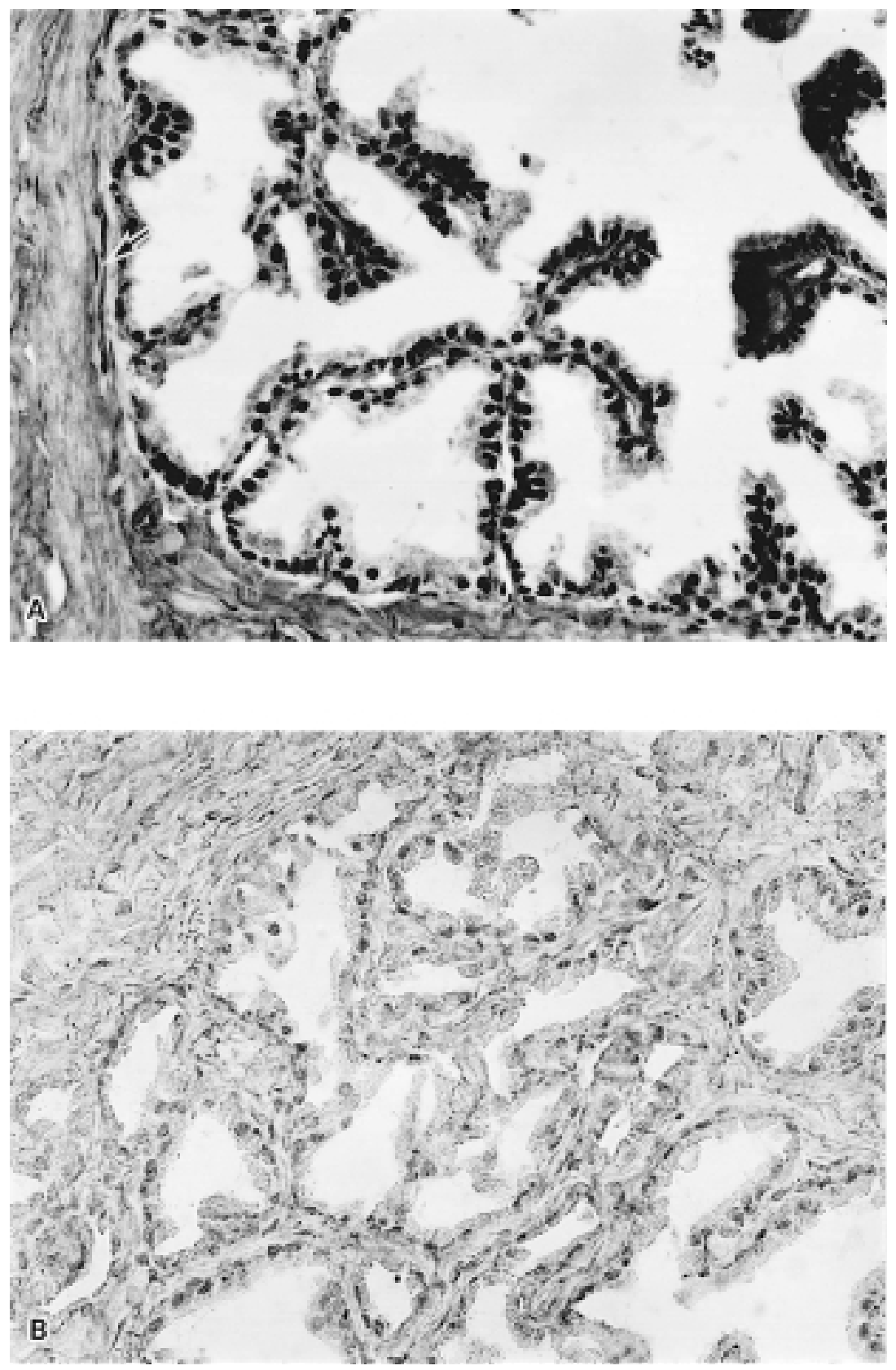

Photo 2. A: Immunolocalization of androgen receptor (AR) in prostate of a dog with spontaneous BPH. The glandular epithelial cells show uniformly intense immunostaining for AR. AR is also localized in the nuclei of the fibro-muscular stromal cells (arrow). Peroxidase-labeled antibody method, $\times 150$.

B: Prostate of a dog with spontaneous BPH after treatment with CMA $0.1 \mathrm{mg} / \mathrm{kg} / \mathrm{day}$. The immunoreaction for AR is negative or very weak in both glandular epithelial cells and fibro-muscular stromal cells. Peroxidase-labeled antibody method, $\times 250$. 
in cortisol and/or corticosterone production and increased or remained in adrenal androgen production. The biological significance of AR in the adrenal cortical cells remains to be further clarified.

It is concluded that CMA $(0.03$ and $0.1 \mathrm{mg} / \mathrm{kg})$ causes regression of spontaneous canine BPH without any histopathological effects on the testes, adrenals or anterior pituitary LH-and ACTH-cells.

\section{REFERENCES}

Beato, M. (1989): Gene regulation by steroid hormones. Cell, 56, 753-762.

Blondeau, J., Baulieu, E. and Robel, P. (1982): Androgen-dependent regulation of androgen nuclear receptor in the rat ventral prostate. Endocrinology, 110, 1926-1932.

Brennan, D.M. and Kraay, R.J. (1963): Chlormadinone acetate, a new highly active getagen-supporting agent. Acta Endocrinol., 44, 367-379.

Carson-Jurica, C.A., Schrader, W.T. and O'Maley, B.W. (1990): Steroid receptor family: Structure and functions. Endocrinol. Rev., 11, 201-220.

Chang, C. and Kokonitis, J. (1988): Identification of a new member of the steroid receptor super-family by he cloning and sequence analysis. Biochem. Biophys. Res. Commun., 155, 971-979.

DeKlerk, D.P., Coffey, D.S., Ewing, L.L., McDerott, I.R., Reiner, W.G., Robinson, C.H., Scott, W.W., Stangberg, J.D., Talalay, P. and Walsh, P.C. (1979): Comparison of spontaneous and experimentally induced canine prostatic hyperplasia. A morphological and histochemical study. J. Clin. Invest., 64, 842-849.

El Etreby, M.F. and Fath, El Bab. (1977): Localization of gonadotrophic hormones in the dog pituitary gland. A study using immunoenzyme histochemistry and chemical staining. Cell Tiss. Res., 183, 167-175.

Forti, G., Salenro, R., Moneti, G., Zoppi, S., Fiorelli, G., Martini, T., Natali, A., Castanitini, A., Serio, M., Martini, L. and Motta, M. (1989): Threemonth treatment with a long-acting gonadotropinreleasing hormone agonist of patients with benign prostate hyperplasia. J. Clin. Endocrinol. Metab., 68, 461-468.

Geller, J., Fishman, J. and Cantor, T.L. (1975): Effect of cyproterone acetate on clinical endocrine and pathological features of benign prostatic hypertrophy. J. Steroid Biochem., 6, 837-843.

Givner, M.L. and Rochefort, J.G. (1972): Effect of syn- thetic progestogens and estradiol-17beta on adrenal function in the rat. Endocrinology, 90, 12381244.

Graham, R.C. and Karnovsky, M.J. (1966): The early stages of absorption of injected horseradish peroxidase in the proximal tubules of mouse kidney. J. Histochem. Cytochem., 14, 291-302.

Harada, M., Kinoshita, Y., Moriyama, M., Kondo, I., Nakahashi, M., Kumagai, H., Sasaki, K. and Hosaka, M.(1994): Histological evaluation of benign prostatic hyperplasia treated by long-term administration of chlormadinone acetate (CMA). Prostate, 25, 147-155.

Huang, J.K., Bartsch, W. and Voit, K.D. (1985): Interaction of an antiandrogen (cyproteorne acetate) with the androgen receptor system and its biological action in the rat ventral prostate. Acta Endocrinol., 109, 569-576.

Ito, Y., Kurosawa, I., Yamanaka, H., Koya, A., Imai, K., Kasaku, N. and Shida, K. (1977): The mechanism of antiandrogenic action of chlormadinone acetate (CMA). Hinyouka Kiyo, 68, 537-552 (in Japanese).

Murakoshi, M., Ikeda, R., Tagawa, M., Iizuka, K., Matsuda, S., Suzuki, M., Mizokami, A. and Watanabe, K. (1994): Effects of antiandrogen, TZP-4238 and chlormadinone acetate (CMA) on the adrenal cortex. Histopathological and immunocytochemical studies. Acta Histochem. Cytochem., 27, 365-372.

Murakoshi, M., Tagawa, M. and Ikeda, R. (2000): Atrophic effects of antiandrogen, chlormadinone acetate (CMA) on dog prostate with spontaneous benign prostatic hyperplasia. J. Toxicol. Sci., 25, 143-150.

Namer, M. (1988): Clinical applications of antiandrogens. J. Steroid Biochem., 31, 719-729.

Okada, K., Oishi, K., Yoshida, K., Sudo, K., Kawase, M. and Nakayama, R. (1988): Study of the effect of an antiandrogen (Oxendolone) on experimentally induced canine prostatic hyperplasia. Urol. Res., 16, 67-72.

Pham-Huu-Trung, M.T., DeSmitter, N., Bogyo, A. and Girard, F. (1984): Effects of cyproterone acetate on adrenal steroidogenesis in vitro. Hormone Res., 20, 108-115.

Starka, L., Motlik, K. and Schreiber, V. (1972): Effect of the antiandrogen cyproterone and cyproterone acetate on male rat adrenals. Physiol. Bohemosl., 21, 233-238.

Syms, A., Norris, J., Panko, W. and Smith, R. (1985): 
Effect of CMA on canine spontaneous BPH.

Mechanism of androgen receptor augmentation. J. Biochem., 260, 455-461.

Takezawa, Y., Fukabori, N., Yamanaka, H., Mieda, M., Honma, S., Kushitani, M. and Hamataki, N. (1992): Effects of the new steroidal antiandrogen TZP-4238 on hormone-induced canine prostatic hyperplasia. Prostate, 21, 315-329.

Takezawa, Y., Ito, K., Suzuki, K., Fukabori, N., Yamanaka, H., Mieda, M., Kamataki, N. and Kushitani, M. (1995): Effect of a new steroidal antiandrogen, TZP-4238, on spontaneously developed canine benign prostatic hyperplasia. Prostate, 27, 321-328.

Tunn, S., Hochstrate, H., Habenicht, V.E. and Krieg, M. (1988): 5 alpha-reductase activity in epithelium and stroma of prostates from intact and castrated dogs treated with andostandiene, the aromatase inhibitor 1-methyl-1,4-androstadiene-3,17-dione, and cyproterone acetate. Prostate, 12, 243-253.

Walsh, P.C. and Wilson, J.D. (1976): The induction of prostatic hypertrophy in the dog with androstanediol. J. Clin. Invest., 57, 1093-1097.

Wilson, J.D. (1980): The pathogenesis of benign prostatic hyperplasia. Am. J. Med., 68, 745-756.

Yoshimura, I. (1997): In "Statistical Analysis of Toxicological Date”, pp. 44-62, Scientist, Tokyo (in Japanese).

Zamboni, L. and McMartino, C. (1967): Buffered picric acid formaldehyde. A new rapid fixation for electron microscopy. J. Cell Biol., 35, 148A. 